\title{
Thalamic, Brainstem, and Cerebellar Glucose Metabolism in the Hemiplegic Monkey
}

\author{
Ichiro Shimoyama, MD,* George W. Dauth, PhD, Sid Gilman, MD, Kirk A. Frey, MD, PhD, \\ and John B. Penney, Jr, MD
}

\begin{abstract}
Unilateral ablation of cerebral cortical areas 4 and 6 of Brodmann in the macaque monkey results in a contralateral hemiplegia that resolves partially with time. During the phase of dense hemiplegia, local cerebral metabolic rate for glucose (ICMRGIc) is decreased significantly in most of the thalamic nuclei ipsilateral to the ablation, and there are slight contralateral decreases. The ICMRGlc is reduced bilaterally in most of the brainstem nuclei and bilaterally in the deep cerebellar nuclei, but only in the contralateral cerebellar correx. During the phase of partial motor recovery, ICMRGlc is incompletely restored in many of the thalamic nuclei ipsilateral to the ablation and completely restored in the contralateral nuclei. In the brainstem and deep cerebellar nuclei, poor to moderate recovery occurs bilaterally. Moderate recovery occurs in the contralateral cerebellar cortex. The findings demonstrate that a unilateral cerebral cortical lesion strongly affects ICMRGlc in the thalamus ipsilaterally and in the cerebellar cortex contralaterally, but in the brainstem bilaterally. Partial recovery of ICMRGlc accompanies the progressive motor recovery. The structures affected include those with direct, and also those with indirect, connections to the areas ablated.
\end{abstract}

Shimoyama I, Dauth GW, Gilman S, Frey KA, Penney JB Jr. Thalamic, brainstem, and cerebellar glucose metabolism in the hemiplegic monkey. Ann Neurol 1988;24:71.8-726

In the monkey, unilateral ablation of cerebral cortical areas 4 and 6 of Brodmann leads to immediate paralysis of the contralateral limbs. With time some recovery of limb function occurs. The mechanisms underlying the partial recovery of limb function have not been determined. Local cerebral metabolic rate for glucose (ICMRGIc) is reduced in the ipsilateral basal ganglia immediately after the ablation [1]. During recovery, ICMRGlc is partially restored in the basal ganglia [2]. The partial restoration of metabolic activity is thought to result from recovery processes derived from unablated areas of the ipsilateral cerebral cortex known to project to the same regions of the basal ganglia as those ablated [2].

In addition to the ipsilateral cerebral cortex, other structures may be involved in the recovery process, including the contralateral cerebral cortex, subcortical nuclei projecting to the basal ganglia, and brainstem structures involved in motor control. The thalamus and the reticular nuclei of the brainstem are closely connected with motor system activities. The precentral cortex has substantial, and often reciprocal, connections with the thalamus, which, in turn, affects other cerebral cortical areas and the basal ganglia. Likewise, cerebral cortical projections to brainstem nuclei provide pathways that may be altered during the recovery process. Thus, the functional and metabolic responses of thalamic and brainstem nuclei to a precentral lesion are likely to be relevant to the processes underlying functional recovery. Finally, the cerebellum must be considered in the interpretation of the effects of ablation of the precentral cortical region. The cerebellum is closely connected with many structures influenced by precentral lesions, including the pontine nuclei, red nucleus, inferior olive, and other brainstem nuclei. The cerebellum provides feedback information to the cerebrum by way of the thalamus.

In the present study we have used the deoxyglucose method to examine changes in ICMRGlc of the major nuclei of the thalamus, brainstem, and cerebellum in the first week after unilateral ablation of areas 4 and 6 of Brodmann and the degree of recovery by the eighth
From the Department of Neurology, The University of Michigan Medical School, Ann Arbor, MI.

Received Dec 22, 1987, and in revised form Mar 24 and May 25, 1988. Accepted for publication May 25, 1988.
Address correspondence to Dr Gilman, Department of Neurology, 1914/0316 Taubman Center, The University of Michigan, 1500 E. Medical Center Dr, Ann Arbor, MI 48109-0316.

"Current address: Deparment of Neurosurgery, Hamamatsu University School of Medicine, 3600 Handa-Cho, Hamamatsu 431-31 Japan. 
week after the ablation. This communication extends our earlier studies, which were restricted to the basal ganglia $[1,2]$.

\section{Methods}

Eighteen Macaca fascicularis monkeys weighing 2.5 to $3.5 \mathrm{~kg}$ were used. Six served as unoperated controls and 12 were used for unilateral ablation of cerebral cortical areas 4 and 6 of Brodmann. Prior to use, all animals were examined neurologically to ensure that they did not have any motor impairment. The ablation was performed in the left cerebral hemisphere as described previously $[1,3]$. Beginning 1 week after the operation, the animals were examined neurologically every week until the deoxyglucose phase of the experiment [3]. Six animals were studied at 1 week after the ablation and 6 were studied at 8 weeks.

The deoxyglucose techniques were identical to those described previously [1]. For the deoxyglucose phase of the experiment, catheters were placed in the femoral vein and artery of the right leg under local anesthesia with xylocaine. The animals were kept in a quiet room for 1 hour, restrained in a primate chair so that the limbs could not move. Careful observation revealed no greater movement of the limbs on either side of the body during the incorporation of deoxyglucose. Moreover, we found no significant differences in the metabolic rates in the cuneate nuclei of the two sides [1], suggesting that differences in limb movement do not account for the differences in metabolic rates observed in the thalamus. No attempt was made to interfere with vision or hearing. Deoxyglucose was administered as an intravenous bolus of $100 \mu \mathrm{Ci} / \mathrm{kg}$ of $\left[{ }^{14} \mathrm{C}\right]$-2-deoxyglucose in $1 \mathrm{ml}$ of saline as described previously $[1,2,4,5]$. The brains were sectioned at $20 \mu \mathrm{m}$ on a cryostat. Three serial sections were taken every $400 \mu \mathrm{m}$ throughout the brain for autoradiography. The sections were placed on coverslips and dried rapidly on a hot plate. The sections and calibrated ${ }^{14} \mathrm{C}$ plastic standards were placed on Kodak SB5 $\mathrm{x}$-ray film in a cassette and exposed for 6 days. Two $20-\mu \mathrm{m}$ serial sections adjacent to those used for autoradiography were processed for histological study [1]. One slide was stained with cresyl violet [6] and the other with $0.3 \%$ osmium tetroxide.

The autoradiographs were analyzed with a spot densitometer interfaced to a microcomputer that was programmed to convert film density values to $1 \mathrm{CMRGlc}$ using ${ }^{14} \mathrm{C}$ standards and plasma glucose and deoxyglucose curves $[1,4,7]$. The lumped and rate constants were those used by Kennedy and colleagues [8]. The ICMRGlc was determined for each structure every $400 \mu \mathrm{m}$ throughout the brain. At each level the measurement consisted of the average of multiple readings from three serial sections at that level. Each structure was measured separately, both ipsilateral and contralateral to the lesion. The final data values used in the analysis consisted of the average from all levels for a particular structure for each animal. The boundaries of thalamic and brainstem structures that were not clearly delineated by surrounding white matter were determined by histological examination of the Nisslstained sections adjacent to the sections used for autoradiography. The boundaries were drawn on the histological slides and the drawings were transferred to acetate overlays that were used as references for measurements made from the autoradiographs. The data from the basal ganglia of these same animals have been reported previously $[1,2]$.

A Wilcoxon signed ranks test was used to evaluate differences in ICMRGlc between the left and the right hemispheres for each structure within each group [9]. A variant of the Kruskal-Wallis one-way layout, which allows multiple comparisons between all groups [10], was applied to the data for each structure in the left hemisphere and the right hemisphere, and to the left-minus-right difference scores for each structure.

\section{Results \\ Clinical Observations}

The clinical observations of these animals were reported in detail in previous publications [1, 2]. Upon recovery from anesthesia, all lesioned animals displayed a dense right hemiplegia that persisted through the first week. The affected limbs were not used for ambulation or feeding. Beyond the first week, the animals' ability to use the affected limbs improved progressively. The resistance to passive movement of these limbs increased gradually, and the amplitude of the deep tendon reflexes in the right limbs increased with time, exceeding that in the left limbs in the sixth to seventh week. By the eighth week, the right leg was used for ambulatory movements, with the right arm occasionally participating. The animals usually reached for objects with the left arm, although the right arm occasionally made accompanying incomplete extension movements. Orienting responses to light cutaneous contact did not recover in the right limbs. The degree of clinical recovery was similar in all animals allowed to survive for 8 weeks.

\section{Histological Results}

The cresyl violet-stained sections were strikingly different between the animals examined at 1 week and those examined at 8 weeks. The main difference was in the degree of inflammatory infiltrate within individual thalamic and brainstem structures. Neuronal loss was evident only in the 8-week animals.

In the 1-week animals there were slight mononuclear cell infiltrates ipsilateral to the lesion in the subcortical white matter, internal capsule, crus cerebri, pontine white matter, and medullary pyramid. There was also an increase in the number of cells with chromatin-pale nuclei and abundant, chromatophilic cytoplasm, presumably reactive astrocytes. A slight mononuclear cell infiltrate without detectable astrocytosis was also present in many thalamic and brainstem structures that receive projections from areas 4 and 6 of Brodmann. The infiltrate was present in the ipsilateral ventral anterior (VA) and ventral lateral (VLA) thalamic nuclei (Fig 1) and bilaterally in the centrum medianum (CM) nucleus. No infiltrate was seen in the anterior, dorsal, lateral, or midline nuclei or those por- 

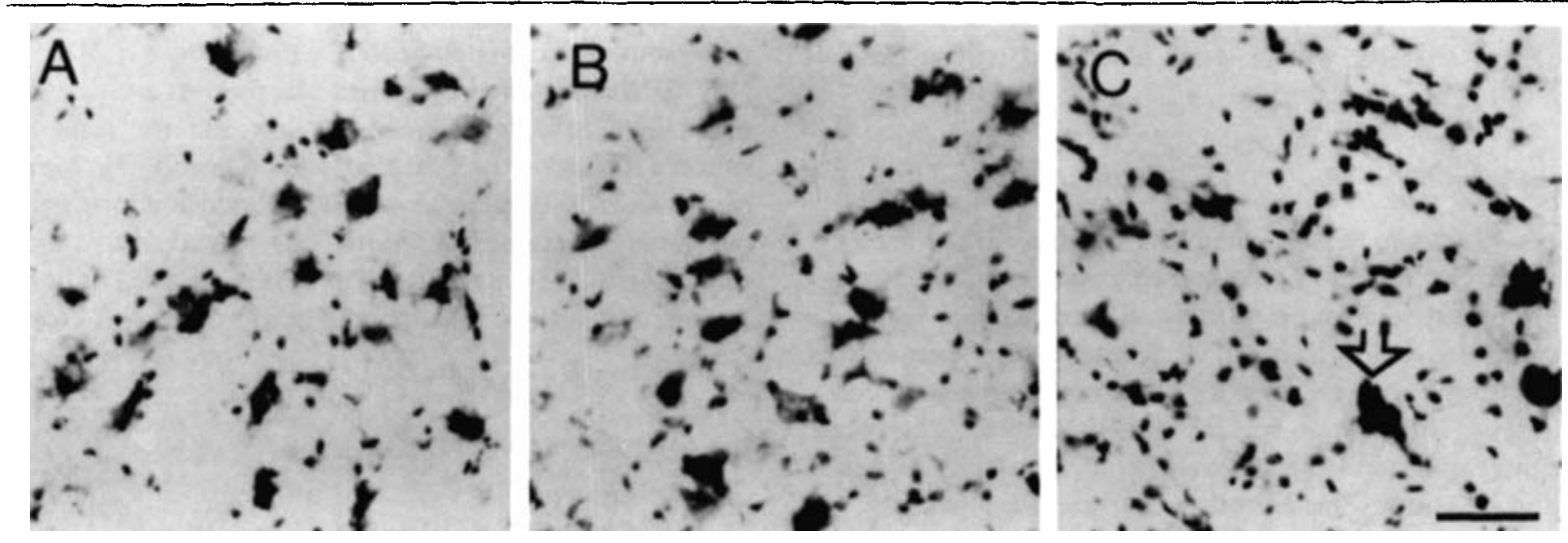

Fig 1. Cresyl violet-stained, $20-\mu \mathrm{m}$ thick sections of the portion of ventral thalamus that projects to area 4 of Brodmann, contralateral ( $A$ ) and ipsilateral (B) to the cerebral cortical lesion in an animal 1 week after area 4 and 6 ablation, and ipsilateral to the lesion $(C)$ in an animal 8 weeks after the ablation. The appearance of the tissue contralateral to the lesion at 8 weeks is the same as that at 1 week. There is a slight increase in the number of cells with small, densely staining nuclei 1 week after ipsilateral ablation of areas 4 and 6. Eight weeks after the ablation the infiltrate is more dense and there is loss of neurons and neuronopbagia (arrow). Bar $=50$ microns.

tions of the ventral posterior (VP) nuclei that project to the postcentral cortex. There were lesser infiltrates in the ipsilateral subthalamic nucleus and in the parvicellular portion of the red nucleus. No infiltrates were seen in the substantia nigra, reticular formation, or cerebellum. No infiltrate was seen in the pontine nuclei or inferior olive.

In the 8-week animals the mononuclear infiltrate was much more prominent in all the areas where it had been detected at 1 week. Astrocytosis was more prominent in the white matter, and there was obvious atrophy of the ipsilateral medullary pyramid. No new areas containing infiltrate could be detected. In all but I animal there was neuronal loss in the portion of ventral thalamus containing neurons that project specifically to area 4 of Brodmann. There was apparent neuronophagia in this region as well (see Fig 1). There was no difference in the location of the cortical ablation site in the 1 animal without detectable neuronal loss.

\section{ICMRGle in Thalamus}

In most of the thalamic nuclei of the left hemisphere, which was ipsilateral to the ablation, ICMRGlc was moderately to substantially reduced 1 week after the ablation (Fig 2). In the thalamus of the right hemisphere, ICMRGIc was only slightly reduced (Fig 3). At 8 weeks ICMRGlc was partially to complerely recovered in the left hemisphere, with a few structures

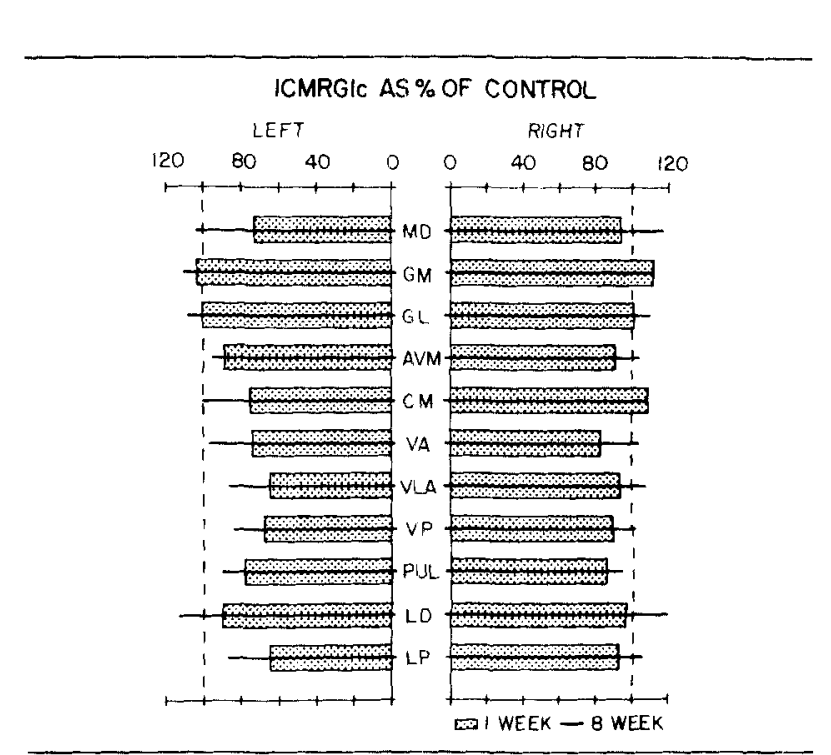

Fig 2. Local cerebral metabolic rate for glucose (ICMRGlc) in the thalamus of animals with unilateral ablation of cerebral cortical areas 4 and 6 of Brodmann at 1 and 8 weeks after ablation. expressed as a percentage of the LCMRGlc in corresponding structures in unoperated control animals. The percentages were calculated based on the mean ICMRGlc for each of the three groups. $A V M=$ anterior ventral and medial nucleus; $C M=$ centrum medianum nucleus; $G L=$ lateral geniculate nucleus; $G M=$ medial geniculate nucleus; $L D=$ lateral dorsal nucleu; $L P=$ lateral posterior nucleus; $M D=$ medial dorsal nucleus; $P U L==$ pulvinar; $V A=$ ventral anterior nucleus; $V L A=$ ventral lat eral nucleus; $V P=$ ventral posterior nucleus.

showing a slight rebound above control levels (see Fig 2 ). In the right hemisphere most of the structures showed ICMRGic slightly above control levels (see Fig 3).

Comparisons were made of the differences in lCMRGlc between the left and right sides. In the 1week group, ICMRGlc was significantly less in the major thalamic nuclei of the left hemisphere compared with the right except for the medial and lateral geniculate nuclei and the anterior thalamic nuclei (Table 1; 

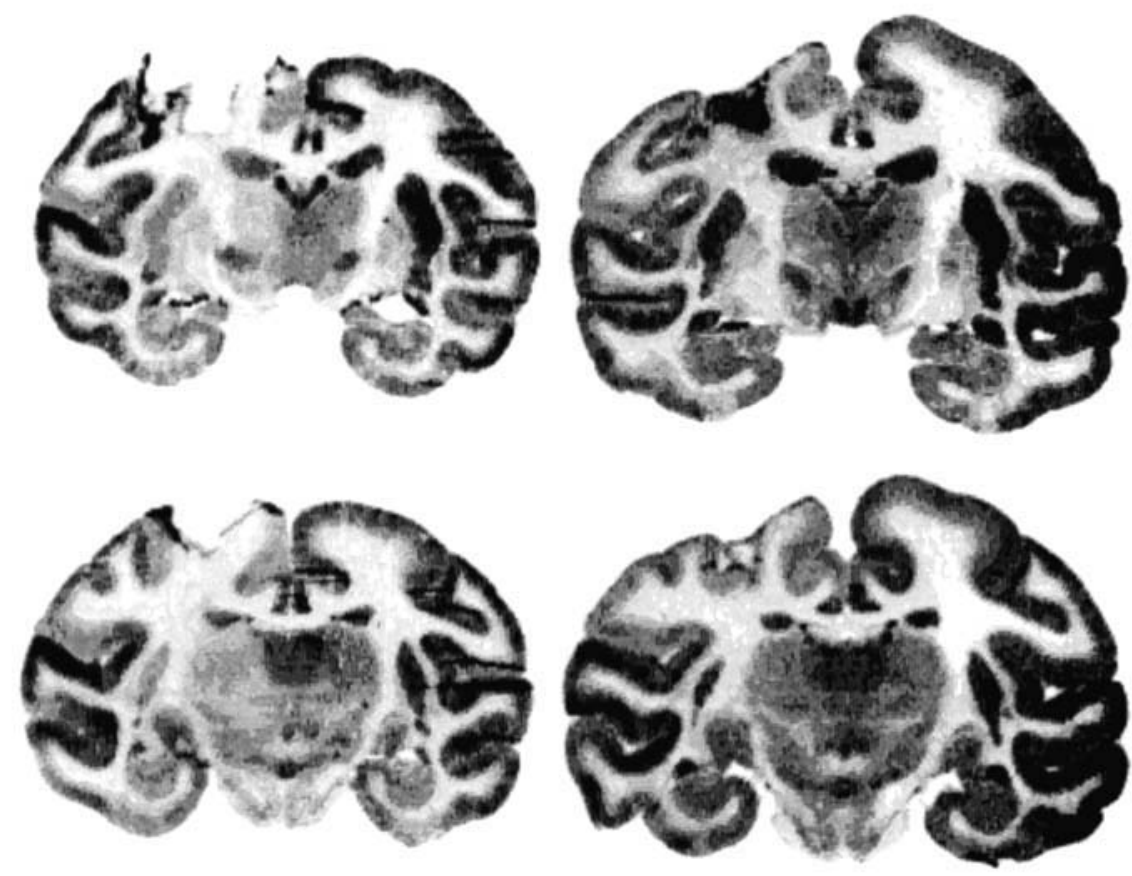

Fig 3. Computer-processed autoradiograph of brain sections through the thalamus from representative animals 1 and 8 weeks after unilateral ablation of cerebral cortical areas 4 and 6 of Brodmann. The gray scale represents increasing optical density from left to right. The two sections on the left are from the same 1-week animal and the two on the right are from the same 8week animal. The gray scale levels were adjusted for each animal to illustrate the left-right differences in the thalamus. The left bemisphere is on the left side of the illustration.

see also Fig 3). In the 8-week group, 1CMRGlc was significantly lower in the left than in the right hemisphere in all structures affected at 1 week except for the pulvinar. In addition, the differences between the left and right sides were significant for the anterior nuclei (see Table 1, Fig 3).

Comparison of animals 1 week after ablation with control animals showed that the significant left-right differences were attributable to a reduction of lCMRGlc in the left hemisphere. The data also suggested a small reduction in ICMRGlc in some of the structures in the right hemisphere (see Fig 3). At 8 weeks, ICMRGlc was moderately to completely recovered in the left hemisphere, and a few structures developed metabolic rates above control levels. In the thalamic nuclei of the right hemisphere, ICMRGlc was at or slightly above control levels (see Table 1, Fig 3).

Analysis of between-group differences for thalamic nuclei of the left hemisphere revealed that only the lateral posterior (LP) nucleus had a significant effect. The right hemisphere showed no significant betweengroup differences. A between-group analysis of the left-right difference scores exposed a complex pattern of significant pairwise comparisons (Table 2, Thalamus). This analysis examined the change in the relationship between the two hemispheres across groups.

In medial dorsal (MD), LP, VLA, and VP nuclei the left-right difference scores were significantly different between control and 1-week groups, and between control and 8-week groups (see Table 2, Thalamus). In these structures ICMRGlc showed evidence of recovery in the left hemisphere (see Table 1, Fig 3), but ICMRGlc also increased in the right hemisphere, and this tended to maintain the left-right asymmetry. In the case of CM and pulvinar nuclei, only the control versus 1-week comparison was significant. At 8 weeks substantial recovery occurred in the left hemisphere and only a moderate elevation was seen in the right hemisphere. The anterior ventral and medial (AVM) nucleus represents a special case in that the asymmetry was significant only at 8 weeks (see Tables 1 and 2, Fig 3 ), and control versus 8 weeks was the only significant between-group comparison. 
Table 1. lCMRGlc in Thalamus ${ }^{a}$

\begin{tabular}{|c|c|c|c|c|c|}
\hline & & Left Hemisphere & Right Hemisphere & Left - Right & Left/Right \\
\hline AVM & $\begin{array}{l}C \\
1 \\
8^{b}\end{array}$ & $\begin{array}{l}35.82(1.6) \\
31.95(4.8) \\
34.29(3.7)\end{array}$ & $\begin{array}{l}36.04(1.8) \\
32.56(4.7) \\
37.46(3.3)\end{array}$ & $\begin{array}{l}-0.22(0.7) \\
-0.61(0.3) \\
-3.17(0.7)\end{array}$ & $\begin{array}{l}0.996(0.02) \\
0.978(0.01) \\
0.908(0.02)\end{array}$ \\
\hline $\mathrm{CM}$ & $\begin{array}{l}C \\
1^{b} \\
8^{b}\end{array}$ & $\begin{array}{l}22.28(1.8) \\
16.62(2.5) \\
22.15(2.5)\end{array}$ & $\begin{array}{l}22.10(1.8) \\
24.18(3.7) \\
24.82(2.1)\end{array}$ & $\begin{array}{r}0.18(0.2) \\
-7.56(1.3) \\
-2.67(0.9)\end{array}$ & $\begin{array}{l}1.009(0.01) \\
0.687(0.01) \\
0.883(0.04)\end{array}$ \\
\hline GL & $\begin{array}{l}C \\
1 \\
8\end{array}$ & $\begin{array}{l}24.48(1.5) \\
24.83(5.2) \\
26.71(3.2)\end{array}$ & $\begin{array}{l}24.93(1.7) \\
24.95(5.2) \\
27.20(2.9)\end{array}$ & $\begin{array}{l}-0.45(0.4) \\
-0.12(0.6) \\
-0.49(0.6)\end{array}$ & $\begin{array}{l}0.984(0.02) \\
0.994(0.03) \\
0.975(0.03)\end{array}$ \\
\hline GM & $\begin{array}{l}C \\
1 \\
8\end{array}$ & $\begin{array}{l}42.51(2.6) \\
42.70(6.4) \\
45.44(3.9)\end{array}$ & $\begin{array}{l}39.82(2.2) \\
46.08(8.0) \\
45.90(3.5)\end{array}$ & $\begin{array}{r}2.70(1.7) \\
-3.38(1.9) \\
-0.46(1.3)\end{array}$ & $\begin{array}{l}1.071(0.04) \\
0.940(0.03) \\
0.988(0.02)\end{array}$ \\
\hline LD & $\begin{array}{l}\mathrm{C} \\
1^{\mathrm{b}} \\
8^{\mathrm{b}}\end{array}$ & $\begin{array}{l}27.13(1.6) \\
24.35(3.3) \\
30.48(4.5)\end{array}$ & $\begin{array}{l}27.15(2.4) \\
26.06(3.5) \\
32.41(4.9)\end{array}$ & $\begin{array}{l}-0.02(0.9) \\
-1.71(0.3) \\
-1.93(0.6)\end{array}$ & $\begin{array}{l}1.018(0.05) \\
0.933(0.01) \\
0.944(0.01)\end{array}$ \\
\hline LP & $\begin{array}{l}C \\
1^{b} \\
8^{b}\end{array}$ & $\begin{array}{l}28.22(1.0) \\
18.29(3.3) \\
24.35(2.3)\end{array}$ & $\begin{array}{l}28.29(0.8) \\
25.98(4.9) \\
29.70(2.3)\end{array}$ & $\begin{array}{l}-0.06(0.4) \\
-7.68(1.7) \\
-5.35(0.8)\end{array}$ & $\begin{array}{l}0.997(0.01) \\
0.707(0.02) \\
0.818(0.03)\end{array}$ \\
\hline MD & $\begin{array}{l}\mathrm{C} \\
1^{\mathrm{b}} \\
8^{\mathrm{b}}\end{array}$ & $\begin{array}{l}32.15(2.1) \\
23.73(3.5) \\
33.70(1.7)\end{array}$ & $\begin{array}{l}32.64(2.1) \\
30.42(4.0) \\
37.89(1.7)\end{array}$ & $\begin{array}{l}-0.49(0.2) \\
-6.69(1.5) \\
-4.19(0.6)\end{array}$ & $\begin{array}{l}0.985(0.01) \\
0.783(0.04) \\
0.889(0.02)\end{array}$ \\
\hline PUL & $\begin{array}{l}C^{b} \\
1^{b} \\
8\end{array}$ & $\begin{array}{l}29.80(1.6) \\
23.02(2.0) \\
26.49(2.1)\end{array}$ & $\begin{array}{l}29.14(1.7) \\
25.20(2.4) \\
27.61(2.1)\end{array}$ & $\begin{array}{r}0.67(0.2) \\
-2.18(0.8) \\
-1.12(0.5)\end{array}$ & $\begin{array}{l}1.024(0.01) \\
0.919(0.02) \\
0.960(0.02)\end{array}$ \\
\hline VA & $\begin{array}{l}\mathrm{C} \\
1^{\mathrm{b}} \\
8^{\mathrm{b}}\end{array}$ & $\begin{array}{l}25.40(1.9) \\
18.95(1.8) \\
24.95(2.7)\end{array}$ & $\begin{array}{l}26.11(2.1) \\
21.42(2.3) \\
26.70(2.8)\end{array}$ & $\begin{array}{l}-0.71(0.4) \\
-2.47(0.6) \\
-1.75(0.4)\end{array}$ & $\begin{array}{l}0.975(0.01) \\
0.892(0.02) \\
0.935(0.01)\end{array}$ \\
\hline VLA & $\begin{array}{l}\mathrm{C} \\
1^{\mathrm{b}} \\
8^{\mathrm{b}}\end{array}$ & $\begin{array}{l}24.30(1.2) \\
15.68(3.0) \\
20.86(2.6)\end{array}$ & $\begin{array}{l}24.34(1.2) \\
22.64(4.0) \\
26.24(2.1)\end{array}$ & $\begin{array}{l}-0.04(0.3) \\
-6.96(1.1) \\
-5.37(1.2)\end{array}$ & $\begin{array}{l}0.999(0.01) \\
0.686(0.02) \\
0.787(0.05)\end{array}$ \\
\hline VP & $\begin{array}{l}C \\
1^{b} \\
8^{b}\end{array}$ & $\begin{array}{l}23.02(1.2) \\
15.62(2.5) \\
19.32(2.3)\end{array}$ & $\begin{array}{l}23.14(1.3) \\
20.62(2.8) \\
23.43(1.8)\end{array}$ & $\begin{array}{l}-0.12(0.2) \\
-5.00(0.7) \\
-4.11(0.7)\end{array}$ & $\begin{array}{l}0.996(0.01) \\
0.749(0.04) \\
0.813(0.04)\end{array}$ \\
\hline
\end{tabular}

${ }^{2}$ Values represent mean and standard error of the mean in parentheses.

bLeft versus right comparison, $p \leq 0.05$ (Wilcoxon signed ranks test).

AVM = anterior ventral and medial nucleus; $C M=$ centrum medianum nucleus; $G L=$ lateral geniculate nucleus; $\mathrm{GM}=$ medial geniculate nucleus; $\mathrm{LD}=$ lateral dorsal nucleus; $\mathrm{LP}=$ lateral posterior nucleus; $\mathrm{MD}=$ medial dorsal nucleus; $P U L=$ pulvinar; $V A=$ ventral anterior nucleus; VLA = ventral lateral nucleus; $\mathrm{VP}=$ ventral posterior nucleus; $\mathrm{C}=$ unoperated control; $1=$ animal examined at 1 week; $8=$ animal examined at 8 weeks.

\section{ICMRGle in Brainstem and Cerebellum}

The ICMRGlc was moderately to substantially reduced bilaterally in brainstem and cerebellar nuclei at 1 week after the ablarion (Fig 4). At 8 weeks, recovery of 1CMRGlc was minimal in most of the affected nuclei of both sides (see Fig 4).

The effects of unilateral precentral cortical ablation on ICMRGlc in the brainstem nuclei appeared to be essentially the same on each side. The only significant left-right differences were in the mesencephalic reticular formation, the pontine nuclei, and the inferior olive (Table 3; see also Fig 4), and the only significant between-group comparisons obtained were for the mesencephalic reticular formation and the pontine nuclei (Table 2). In the remaining structures, the data demonstrated bilateral reduction of ICMRGlc at 1 week, with marginal to moderate recovery bilaterally at 8 weeks. The ICMRGlc in the vestibular nuclei might be elevated at both 1 and 8 weeks.

The deep cerebellar nuclei showed no significant left-right or between-group differences. The data did suggest a moderate bilateral reduction for all the cerebellar nuclei at 1 week, and this reduction appeared to be maintained at 8 weeks (see Table 3, Fig 4). The flocculus showed a significant left-right difference at 1 week, with ICMRGic in the right hemisphere less than in the left. At 8 weeks there was no significant leftright difference, and both sides were above control levels (see Table 3, Fig 4). The remainder of the cerebellar cortex was not analyzed quantitatively, but consistent alterations in the patterns of activity were seen in 1-week animals and a different pattern was seen in 
Table 2. Multiple Comparisons of ICMRGlc Left-Right Difference Scores

\begin{tabular}{|c|c|c|c|}
\hline & $\begin{array}{l}\text { Control vs } \\
1 \text {-Week } \\
\text { Animals }\end{array}$ & $\begin{array}{l}\text { Control vs } \\
\text { 8-Week } \\
\text { Animals }\end{array}$ & $\begin{array}{l}\text { 1-Week vs } \\
\text { 8-Week } \\
\text { Animals }\end{array}$ \\
\hline \multicolumn{4}{|l|}{ Thalamus } \\
\hline AVM & - & * & * \\
\hline $\mathrm{CM}$ & * & - & - \\
\hline GL & - & - & - \\
\hline GM & - & - & - \\
\hline LD & - & - & - \\
\hline LP & $*$ & * & - \\
\hline MD & ${ }^{*}$ & $*$ & - \\
\hline PUL & * & - & - \\
\hline VA & - & - & - \\
\hline VLA & * & $*$ & - \\
\hline VP & * & * & - \\
\hline \multicolumn{4}{|c|}{$\begin{array}{l}\text { Brainstem and } \\
\text { cerebellum }\end{array}$} \\
\hline FRG & - & - & - \\
\hline FRS & - & - & - \\
\hline FRT & * & * & - \\
\hline RTP & - & - & - \\
\hline CNL & - & - & - \\
\hline FL & - & - & - \\
\hline GPO & * & - & - \\
\hline $\mathrm{OI}$ & - & - & - \\
\hline NDC & - & - & - \\
\hline NFC & - & - & - \\
\hline NIC & - & - & - \\
\hline VES & - & - & - \\
\hline
\end{tabular}

${ }^{*} p \leq 0.05$ (Kruskal-Wallis multiple comparison); for all other abbreviations see footnotes to Tables 1 and 3 .

8-week animals (Fig 5). At 1 week the right cerebellar cortex had a slight but consistent reduction in activity as compared with the left. At 8 weeks both the right vermal and intermediate zones were reduced compared with the left, but the right hemisphere appeared equal in activity to the left hemisphere.

\section{Discussion}

Unilateral ablation of cerebral cortical areas 4 and 6 of Brodmann resulted in a moderate to substantial reduction of ICMRGlc in the ipsilateral thalamus at 1 week, and by 8 weeks there was considerable recovery. The ipsilateral thalamic nuclei and their responses to the ablation could be divided into three groups according to their thalamocortical and corticothalamic relationships.

The first group has important reciprocal ipsilateral connections with the ablated cortex and includes VA, VLA, and VP nuclei. At 1 week, ICMRGlc ipsilateral to the ablation was 65 to $75 \%$ of control values. The reduction in the VLA and VP nuclei was not surprising, considering their strong reciprocal connections with areas 4 and 6 of Brodmann $[11,12]$. Likewise, the VA nucleus has an important reciprocal relation-

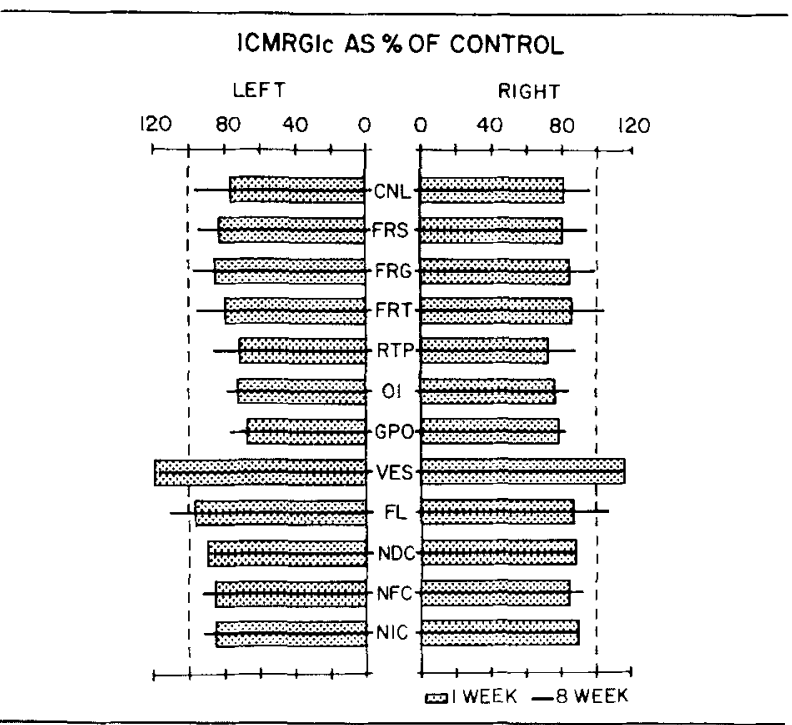

Fig 4. Local cerebral metabolic rate for glucose (lCMRGlc) in the brainstem of animals with unilateral ablations of cerebral cortical areas 4 and 6 of Brodmann at 1 and 8 weeks after ablation, expressed as a percentage of the lCMRGlc in corresponding structures in unoperated control animals. The percentages were calculated based on the mean ICMRGlc for each of the three groups. $C N L=$ lateral cuneate nucleus; $F L=$ flocculus; $F R G=$ magnocellular reticular formation; $F R S=$ parvicellular reticular formation; $F R T=$ mesencephalic reticular formation; $G P O=$ pontine nuclei; $N D C=$ dentate nucleus; $N F C=$ fastigial $n u$ cleus; $N I C=$ interpositus; $O I=$ inferior olive; $R T P=$ pontine reticular formation; $V E S=$ vestibular nucleus.

ship with area 6 [12]. At 8 weeks there was moderate recovery of ICMRGlc in VLA and VP nuclei and almost complete recovery in the VA nucleus. Degeneration of neurons in VLA and VP nuclei could limit the degree of recovery of 1 CMRGlc in these structures.

The second group of nuclei, the MD and CM nuclei, receive important corticothalamic projections from the ablated cortex, with minor thalamocortical projections. At 1 week the MD and CM nuclei had ICMRGlc rates that were $74 \%$ and $75 \%$ of control values, respectively, and by 8 weeks both exhibited complete recovery. The MD nucleus receives strong and partially overlapping projections from both area 4 and area 6 of Brodmann, and the thalamocortical projections from the MD nucleus to areas 4 and 6 are relatively minor [13-16]. The main projection from the MD nucleus is to the frontal association cortex. Likewise, the CM nucleus receives an important projection from area 4 , and a less important projection to its medial portion comes from area 6. Reciprocal thalamocortical projections from the $C M$ nucleus are sparse $[14,17,18]$, but both $\mathrm{CM}$ and $\mathrm{MD}$ nuclei receive projections from the contralateral (unablated) cortex [11, 12, 14].

The third group consists of the lateral dorsal (LD), 
Table 3. ICMRGlc in Brainstem and Cerebellum ${ }^{\mathrm{a}}$

\begin{tabular}{|c|c|c|c|c|c|}
\hline & & Left Hemisphere & Right Hemisphere & Left - Right & Left/Right \\
\hline FRG & $\begin{array}{l}\mathrm{C} \\
1 \\
8\end{array}$ & $\begin{array}{l}22.64(1.9) \\
19.20(2.1) \\
21.85(1.7)\end{array}$ & $\begin{array}{l}22.32(1.7) \\
19.00(2.0) \\
22.14(1.8)\end{array}$ & $\begin{array}{r}0.32(0.2) \\
0.20(0.2) \\
-0.30(0.2)\end{array}$ & $\begin{array}{l}1.013(0.01) \\
1.007(0.01) \\
0.988(0.01)\end{array}$ \\
\hline FRS & $\begin{array}{l}C \\
1 \\
8\end{array}$ & $\begin{array}{l}18.60(1.5) \\
15.26(1.5) \\
17.43(1.7)\end{array}$ & $\begin{array}{l}18.35(1.5) \\
14.92(1.5) \\
17.43(1.8)\end{array}$ & $\begin{array}{l}0.24(0.2) \\
0.34(0.2) \\
0.00(0.2)\end{array}$ & $\begin{array}{l}1.013(0.01) \\
1.025(0.01) \\
1.003(0.01)\end{array}$ \\
\hline FRT & $\begin{array}{l}C^{b} \\
1^{b} \\
8^{b}\end{array}$ & $\begin{array}{l}20.42(1.2) \\
16.05(2.2) \\
19.24(1.5)\end{array}$ & $\begin{array}{l}19.86(1.2) \\
17.28(2.1) \\
20.95(1.7)\end{array}$ & $\begin{array}{r}0.56(0.2) \\
-1.23(0.4) \\
-1.71(0.3)\end{array}$ & $\begin{array}{l}1.029(0.01) \\
0.924(0.02) \\
0.920(0.01)\end{array}$ \\
\hline RTP & $\begin{array}{l}\mathrm{C} \\
1 \\
8\end{array}$ & $\begin{array}{l}21.60(1.4) \\
15.50(2.4) \\
18.67(1.3)\end{array}$ & $\begin{array}{l}21.70(1.1) \\
15.67(2.7) \\
19.01(1.2)\end{array}$ & $\begin{array}{l}-0.10(0.6) \\
-0.17(0.3) \\
-0.34(0.2)\end{array}$ & $\begin{array}{l}0.993(0.03) \\
0.997(0.02) \\
0.979(0.01)\end{array}$ \\
\hline CNL & $\begin{array}{l}C \\
1 \\
8\end{array}$ & $\begin{array}{l}22.86(1.8) \\
17.32(2.0) \\
21.82(2.0)\end{array}$ & $\begin{array}{l}22.36(1.8) \\
18.39(2.5) \\
21.76(2.3)\end{array}$ & $\begin{array}{r}0.50(0.8) \\
-1.07(1.0) \\
0.06(0.6)\end{array}$ & $\begin{array}{l}1.025(0.04) \\
0.959(0.05) \\
1.011(0.03)\end{array}$ \\
\hline $\mathrm{FL}$ & $\begin{array}{l}\mathrm{C} \\
1^{\mathrm{b}} \\
8\end{array}$ & $\begin{array}{l}42.95(3.7) \\
40.53(4.1) \\
46.62(4.3)\end{array}$ & $\begin{array}{l}41.05(3.6) \\
36.56(3.2) \\
44.94(4.3)\end{array}$ & $\begin{array}{l}1.90(0.9) \\
3.97(1.4) \\
1.68(1.1)\end{array}$ & $\begin{array}{l}1.049(0.03) \\
1.104(0.03) \\
1.042(0.03)\end{array}$ \\
\hline GPO & $\begin{array}{l}\mathrm{C} \\
1^{\mathrm{b}} \\
8\end{array}$ & $\begin{array}{l}22.88(2.1) \\
15.31(2.1) \\
17.40(2.6)\end{array}$ & $\begin{array}{l}22.46(1.9) \\
17.87(2.3) \\
18.65(2.2)\end{array}$ & $\begin{array}{r}0.43(0.4) \\
-2.55(0.5) \\
-1.25(0.6)\end{array}$ & $\begin{array}{l}1.016(0.02) \\
0.857(0.03) \\
0.918(0.04)\end{array}$ \\
\hline OI & $\begin{array}{l}C \\
1 \\
8^{b}\end{array}$ & $\begin{array}{l}30.96(3.6) \\
22.51(2.3) \\
24.14(2.3)\end{array}$ & $\begin{array}{l}30.85(3.6) \\
23.75(2.6) \\
26.12(1.9)\end{array}$ & $\begin{array}{r}0.11(0.2) \\
-1.24(0.6) \\
-1.35(0.5)\end{array}$ & $\begin{array}{l}1.004(0.01) \\
0.952(0.02) \\
0.942(0.02)\end{array}$ \\
\hline NDC & $\begin{array}{l}C \\
1 \\
8\end{array}$ & $\begin{array}{l}36.78(3.5) \\
32.80(4.9) \\
31.54(2.9)\end{array}$ & $\begin{array}{l}36.38(3.7) \\
32.24(5.1) \\
31.70(2.8)\end{array}$ & $\begin{array}{r}0.40(0.5) \\
0.56(1.3) \\
-0.16(0.4)\end{array}$ & $\begin{array}{l}1.014(0.02) \\
1.023(0.04) \\
0.993(0.01)\end{array}$ \\
\hline NFC & $\begin{array}{l}\mathrm{C} \\
1 \\
8\end{array}$ & $\begin{array}{l}28.55(3.5) \\
24.35(5.5) \\
26.27(3.1)\end{array}$ & $\begin{array}{l}28.80(3.5) \\
24.32(5.0) \\
26.32(3.2)\end{array}$ & $\begin{array}{r}-0.25(0.2) \\
0.03(0.6) \\
-0.05(0.2)\end{array}$ & $\begin{array}{l}0.991(0.01) \\
0.987(0.02) \\
0.999(0.01)\end{array}$ \\
\hline NIC & $\begin{array}{l}C \\
1 \\
8\end{array}$ & $\begin{array}{l}31.13(3.7) \\
26.26(5.2) \\
28.16(2.9)\end{array}$ & $\begin{array}{l}30.73(3.5) \\
27.84(6.1) \\
27.94(3.0)\end{array}$ & $\begin{array}{r}0.40(0.4) \\
-1.58(1.2) \\
0.22(0.5)\end{array}$ & $\begin{array}{l}1.013(0.01) \\
0.962(0.03) \\
1.009(0.02)\end{array}$ \\
\hline VES & $\begin{array}{l}C^{b} \\
1 \\
8\end{array}$ & $\begin{array}{l}33.79(1.8) \\
39.31(4.6) \\
38.39(1.7)\end{array}$ & $\begin{array}{l}32.36(1.7) \\
38.52(4.3) \\
38.42(1.6)\end{array}$ & $\begin{array}{r}1.43(0.8) \\
0.80(0.3) \\
-0.03(0.5)\end{array}$ & $\begin{array}{l}1.045(0.02) \\
1.018(0.01) \\
0.999(0.01)\end{array}$ \\
\hline
\end{tabular}

${ }^{2} V$ alues represent mean and standard error of the mean in parentheses.

${ }^{\mathrm{b}}$ Left versus right comparison, $p \leq 0.05$ (Wilcoxon signed ranks test).

$\mathrm{CNL}=$ lateral cuneate nucleus; FL = flocculus; FRG = magnocellular reticular formation; FRS $=$ parvicellular reticular formation; FR $\Gamma=$ mesencephalic reticular formation; $\mathrm{GPO}=$ pontine nuclei; $\mathrm{NDC}=$ dentate nucleus; $\mathrm{NFC}=$ fastigial nucleus; $\mathrm{NIC}=$ interpositus; $\mathrm{OI}=$ inferior olive; RTP = pontine reticular formation; VES = vestibular nucleus; $\mathrm{C}=$ unoperated control; $1=$ animal examined at 1 week; $8=$ animal examined at 8 weeks; ICMRGlc $=$ local cerebral metabolic rate for glucose.

LP, and pulvinar nuclei and the AVM complex, all of which have relatively minor corticothalamic or thalamocortical relations with cerebral cortical areas 4 and 6 of Brodmann. At 1 week, these structures had metabolic rates that ranged from 65 to $89 \%$ of control values. The $\mathrm{LD}$ nucleus may receive a sparse projection from agranular cortex [12], but its main relationship is with the cingulate gyrus [19]. The AVM complex, like the LD nucleus, is associated primarily with the cingulate gyrus. Its main subcortical input is via the fornix and the mammilothalamic tract; however, a small projection from area 6 has been reported [12]. The fact that these structures were minimally affected at 1 week probably reflects the sparse corticothalamic projections from areas 4 and 6 and perhaps a complete absence of thalamocortical projections to these areas. The cause for the large reduction in the LP nucleus is less easily explained, since corticothalamic projections from areas 4 and 6 are relatively minor, as are the reciprocal projections, if any exist $[11,12]$. The LP nucleus projects primarily to the dorsal and medial parietal cortex, area 5 of Brodmann. This relationship may be responsible for the substantial reduction of metabolic activity in the LP nucleus because of alterations of neuronal activity in area 5 owing to decreased corticocortical activity from the ablated cortex. A sumilar argument can be made for the pulvinar, which receives only a small projection from agranular cortex. 

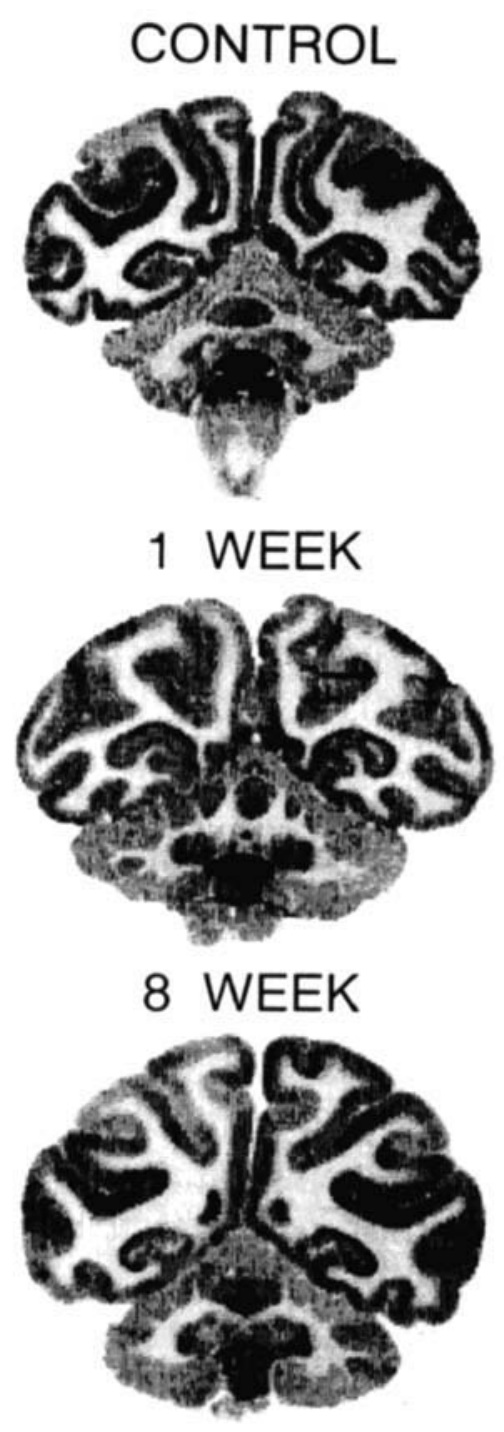

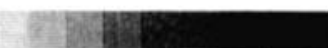

Fig 5. Computer-processed autoradiograph of brain sections through the cerebellum from representative animals: (upper section) control animal; (middle section) animal 1 week after unilateral ablation of cerebral cortical areas 4 and 6 of Brodmann; (lower section) animal 8 weeks after an identical unilateral ablation. The gray scale represents increasing optical density from left to right. The gray scale levels were adjusted for each animal to illustrate the left-right differences in the cerebellar cortex. The left hemisphere is on the left side of the illustration.

The effects of the ablation on ICMRGlc in the brainstem nuclei and cerebellum fell into two groups: (1) those with significant asymmetries and (2) those with symmetrically altered ICMRGic. In the first group were structures with significant asymmetries in ICMRGlc at 1 week (flocculus and pontine nuclei); at 8 weeks (inferior olive); and at both 1 and 8 weeks (mesencephalic reticular formation). The cerebellar cortex should also be included in this last group. In the remaining brainstem structures there were no significant asymmetries at 1 or 8 weeks; however, there were clear bilateral reductions in most of these nuclei at 1 week, with slight to substantial bilateral recovery at 8 weeks. An exception was the vestibular complex, where metabolic rate was increased compared with control at both 1 and 8 weeks after the ablation. Many of the affected brainstem nuclei receive bilateral projections from the ablated cortex [17, 20-25], which is consistent with the finding of symmetrical changes in ICMRGIC.

Phagocytic infiltration and gliosis following central nervous system ablations can contribute to changes in metabolic rates [25-28]. In the monkey some phagocytic activity and gliosis occur at 1 week after cerebral cortical ablation $\{1,2\}$. These processes enhance metabolic activity and thus tend to mask the reductions in ICMRGlc resulting from decreased synaptic activity. At 8 weeks, when there was some recovery of ICMRGk, gliosis would tend to contribute to these increases in metabolic rate. This factor presents a problem for the interpretation of the increases in ICMRGlc within structures such as the VA, VLA, VP, and CM nuclei. In structures such as the MD and LP nuclei and the pulvinar there was little or no infiltration or gliosis at 1 week or 8 weeks. Thus, gliosis is not likely to have been involved in the recovery of ICMRGlc in these structures.

Despite a marked reduction of metabolic activity in many first-order and second-order projection sites, the affected synaptic beds were very active after the ablation. Chronic single unit recordings from the neostriatum in awake monkeys with ablation of areas 4 and 6 of Brodmann over the 8-week interval from the time of the ablation revealed an increase in discharge rate and a striking change in the pattern of activity in comparison with unlesioned animals [29]. In the globus pallidus, a second-order site, neuronal activity was preserved, although overall firing rate was somewhat decreased [30].

The effects of cortical ablation in the monkey are relevant to the clinical effects of injury to the cerebral cortex in the human. Initially decreased, metabolic activity recovers with time, in parallel with a definite but limited functional recovery of limb movement. Some of the changes in metabolic activity may be related to clinical recovery. The changes in brainstem activity, particularly within the vestibular nuclei, may represent compensatory processes involved in the restoration of postural reflexes.

Supported in part by grant NS 19613 from NINCDS and grant R231-84 from the United Cerebral Palsy Education and Research Foundation, Inc. Dr Frey was a trainee on grant GM 07863 from the National Institutes of Health. 


\section{References}

1. Dauth GW, Gilman S, Frey KA, Penney JB Jr. Basal ganglia glucose utilization after recent precentral ablation in the monkey. Ann Neurol 1985;17:431-438

2. Gilman S, Dauth G, Frey KA, Penney JB. Experimental hemiplegia in the monkey: basal ganglia glucose activity during recovery. Ann Neurol 1987;22:370-376

3. Gilman S, Lieberman JS, Marco LA. Spinal mechanisrns underlying the effects of unilateral ablation of areas 4 and 6 in monkeys. Brain 1974;97:49-64

4. Sokoloff L, Reivich M, Kennedy C, et al. The $\left[{ }^{14} \mathrm{C}\right]$ deoxyglucose method for the measurement of local cerebral glucose utilization: theory, procedure and normal values in the conscious and anesthetized albino rat. J Neurochem 1977;28:897-916

5. Sokoloff $\mathbf{L}$. Localization of functional activity in the central nervous system by measurement of glucose utilization with radioactive deoxyglucose. J Cereb Blood Flow Metab 1981;1:7-36

6. Luna LG. Manual of histologic staining methods of the Armed Forces Institute of Pathology. 3rd ed. New York: McGraw-Hill, 1968

7. Dauth GW, Frey KA, Gilman S. A densitometer for quantitative autoradiography. J Neurosci Methods 1983;9:243-251

8. Kennedy C, Sakurada O, Shinohara M, et al. Local cerebral glucose utilization in the normal conscious macaque monkey. Ann Neurol 1978;4:293-301

9. Siegel S. Nonparametric statistics for the behavioral sciences. New York: McGraw-Hill, 1956

10. Hollander M, Wolfe DA. Nonparametric statistical methods. New York: Wiley, 1973

11. Künzle $\mathrm{H}$. Thalamic projections from the precentral motor cortex in Macaca fascicularis. Brain Res 1976;105:253-267

12. Künzle $H$. An autoradiographic analysis of the efferent connections from premotor and adjacent prefrontal regions (areas 6 and 9) in Macaca fascicularis. Brain Behav Evol 1978;15:185234

13. Akert K, Hartmann-von Monakow K, Künzle H. Projection of precentral motor cortex upon nucleus medialis dorsalis thalami in the monkey. Neurosci Lett 1979;11:103-106

14. Akert K, Hartmann-von Monakow K. Relationships of the precentral, premotor and prefrontal cortex to the mediodorsal and intralaminar nuclei of the monkey thalamus. Acta Neurobiol Exp (Warsz) 1980;40:7-24

15. Schell GR, Strick PL. The origin of thalamic inputs to the arcuate premotor and supplementary motor areas. $J$ Neurosci 1984;4:539-560

16. Goldman-Rakic PS, Porrino LJ. The primate mediodorsal (MD) nucleus and its projection to the frontal lobe. J Comp Neurol $1985 ; 242 ; 535-560$

17. Leichnetz GR. Afferent and efferent connections of the dorsolateral precentral gyrus (area 4, hand/arm region) in the macaque monkey, with comparisons to area 8. J Comp Neurol 1986; 254:460-492

18. Jones EG, Leavitt RY. Retrograde axonal transport and the demonstration of non-specific projections to the cerebral cortex and the striatum from the thalamic intralaminar nuclei in the rat, cat and monkey. J Comp Neurol 1975;154:349-378

19. Carpenter MB, Sutin J. Human neuroanatomy. 8th ed. Baltimore: Williams \& Wilkins, 1983

20. Wiesendanger $\mathrm{R}$, Wiesendanger M. Cerebello-cortical linkage in the monkey as revealed by transcellular labeling with lectin wheat germ agglutinin conjugated to the marker horseradish peroxidase. Exp Brain Res 1985;59:105-117

21. Brodal P. Principles of organization of the monkey corticopontine projection. Brain Res 1978;148:214-218

22. Brodal $P$. The cortical projection to the nucleus reticularis tegmenti pontis in the thesus monkey. Exp Brain Res 1980;38:1927

23. Hartmann-von Monakow K, Akert K, Künzle H. Projections of precentral and premotor cortex to the red nucleus and other midbrain areas in Macaca fascicularis. Exp Brain Res 1979;34: 91-105

24. Kuypers HGJM, Lawrence DG. Cortical projections to the red nucleus and the brain stem in the rhesus monkey. Brain Res $1967 ; 4: 151-188$

25. Cheema S, Rustioni A, Whitsel BI. Sensorimotor cortical projections to the primate cuneate nucleus. J Comp Neurol 1985; 240:196-211

26. Cooper RM, Thurlow GA, Rooney BJ. 2-deoxyglucose uptake and histologic changes in rat thalamus after neocortical ablations. Exp Neurol 1984;83:134-143

27. Agranoff BW, Frey KA. A regional metabolic contrast method for the study of brain pathology. Ann Neurol 1984;15 (suppl):S93-S97

28. Frey KA, Agranoff BW. Barbiturate-enhanced detection of brain lesions by carbon-14-labeled 2-deoxyglucose autoradiography. Science 1983;219:879-881

29. Aldridge JW, Gilman S, Dauth GW. Changes in spontaneous single unit activity in the putamen following area 4 and 6 ablation in primates. Soc Neurosci Abstr 1985;11:684

30. Aldridge JW, Gilman S, Dauth GW. Changes in spontaneous single unit activity in the globus pallidus following area 4 and 6 ablation in primates. Soc Neurosci Abstr 1986;12:651 